
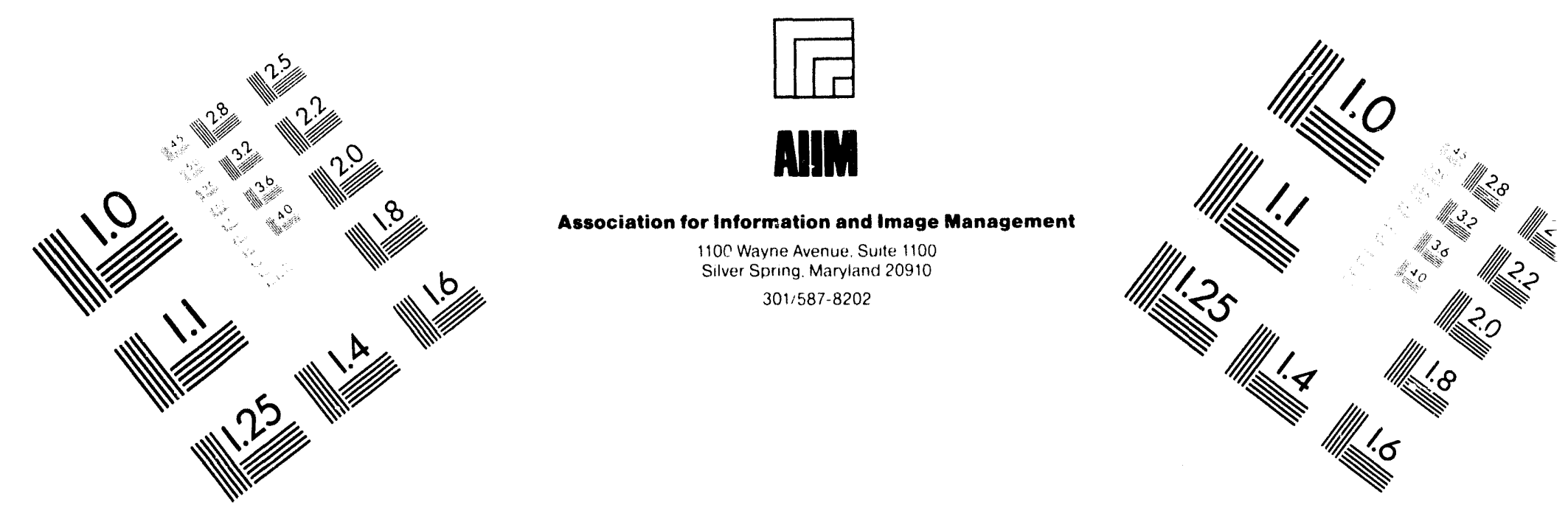

\title{
Centimeter
}

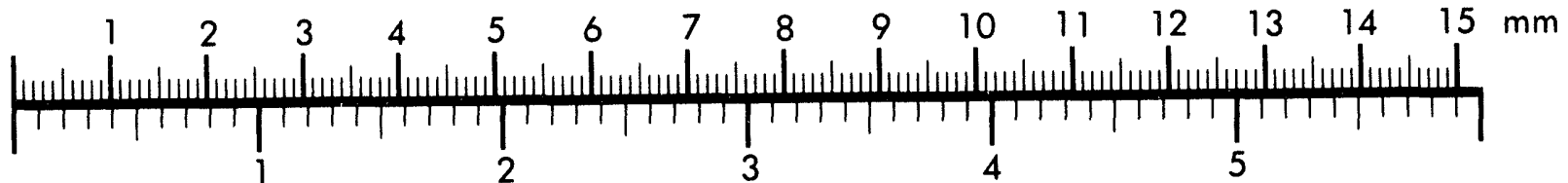
Inches
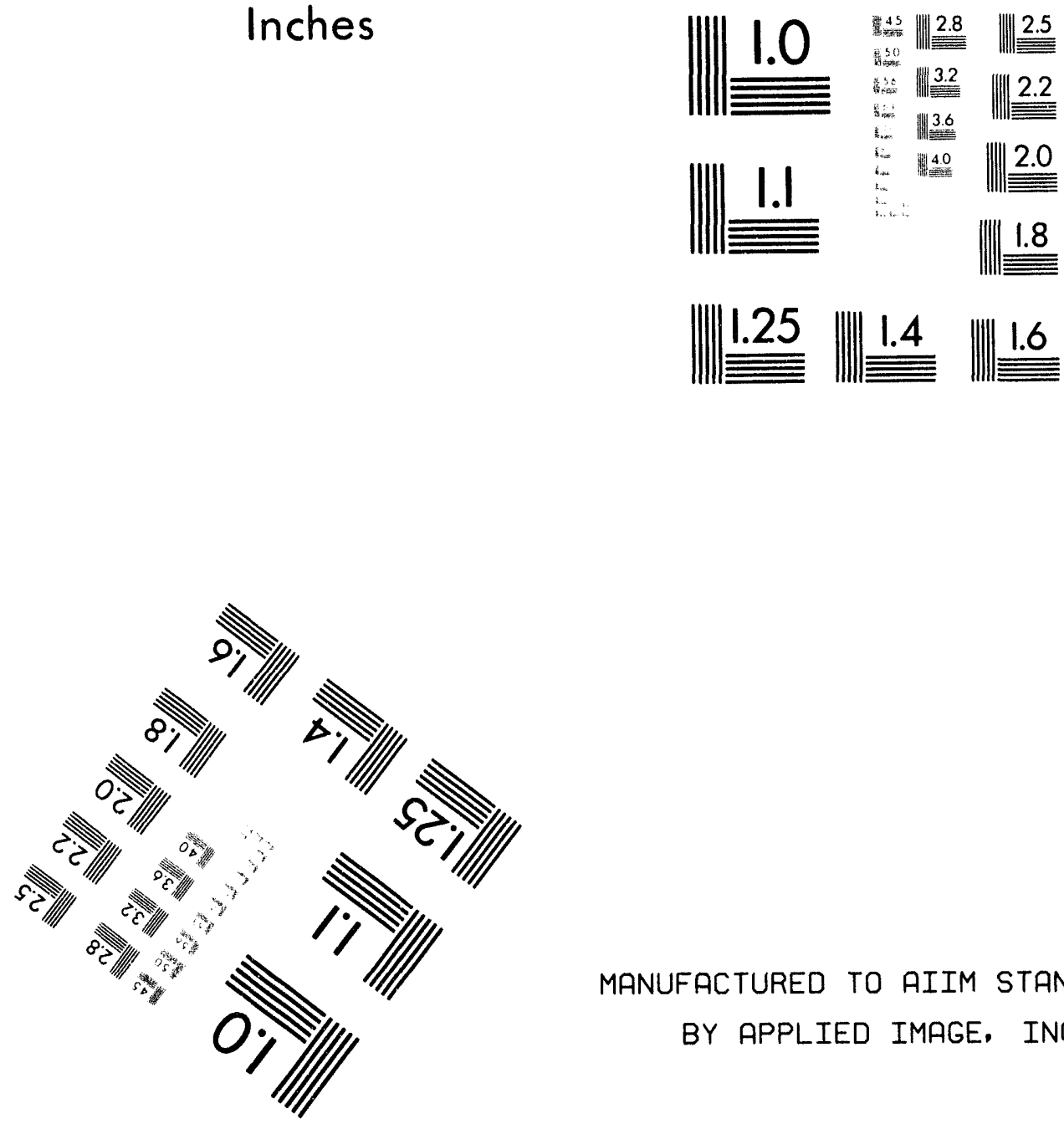

MANUFACTURED TO AIIM STANDARDS

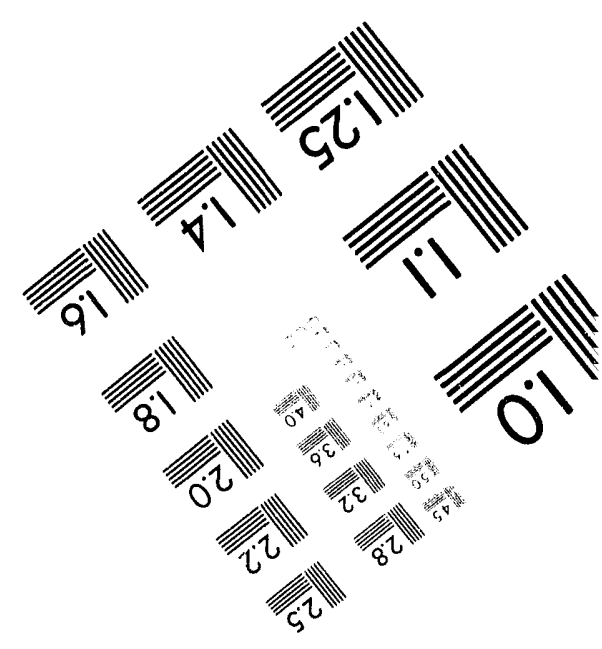






\section{GENERAL (3) ELECTRIC}

HANFORD ATOMIC PRODUCTS OPERATION - RICHLAND, WASHINGTON

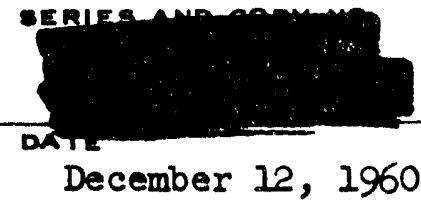

K REACTOR--HCR SIEEVES

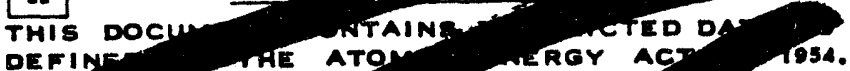
ITPY MITTAL ATOM DISCLOSHCT ITS IT NANS IN AML MER TO AN U MORIZED CRSON IS F MTED.

OTHER OFFICIAL CLABSIFIED INFORMATION

THIS MATERIAL CONTAINS INFORMATION AFFECTING THE NATIONAL DEFENSE OF THE UNITED STATEB WITHIN THE MEANING OF THE EBPIONAGE LAWS. TITLE 18, U. 8. C., BECS. MS AND TOA, THE TRANB-

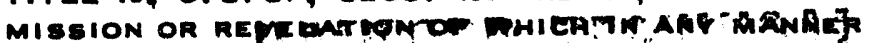
TO AN UNAUTHOKIzED PEREON IS PROHIBITED DY LAW.

\section{THIS DOCUMENT MUT TOTOT UNATTENDED} THIS DOCUMENT MIN TE LEFT UNATTENDED TO IT. WHEN NM DHE, IT MUST BE STOREP GUARDED W WHILE IT IS YOUR POS. CLASSI FILES, IT IS YOUR O.. WGILITY TO TH UJECT AND FROM ANY

RESIDENCE IS PROHIM IT IS NOT TO DE ITAIN THEM FROM IELATED ISSUING FIMS TO SION IN THE G. PROVIDED BELOW.

\begin{tabular}{|c|c|c|c|c|c|c|}
\hline ROUTE TO: & PAYROLL NO. & LOCATION & FILES ROUTE & BIGNATURE & AND & DATE \\
\hline$=-x \cdot \mu c i=1$ & 49.5 & $17(: 1)$ & . & $1 \quad \ldots-$ & 1 & \\
\hline
\end{tabular}

mar have aCCEss PPROVED LOCKED REPO UNAUTHORIZED PERT MAY MAVE ACCESD

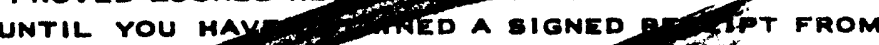
KEEP IT A CONTENTS WITH OIMITS OF TS MTTAL TO, AND N YOUR PLACE TED. IF ADDITI CPIES ARE REQUIRED, RSONB READING TH UCUMENT ARE REQUESTED TITLE 


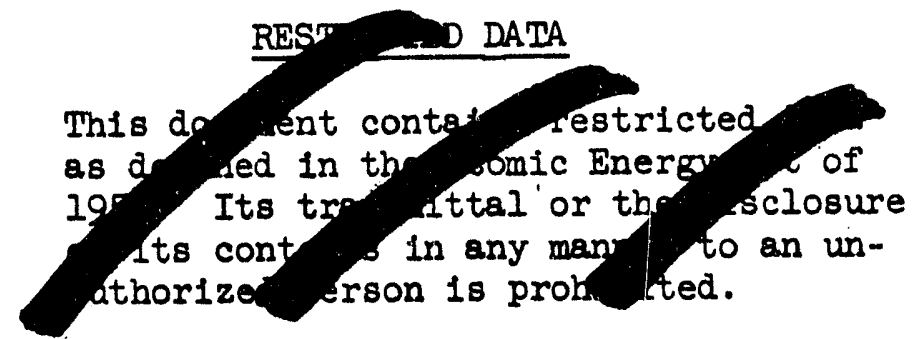

Th1s document consists of 4 pages.
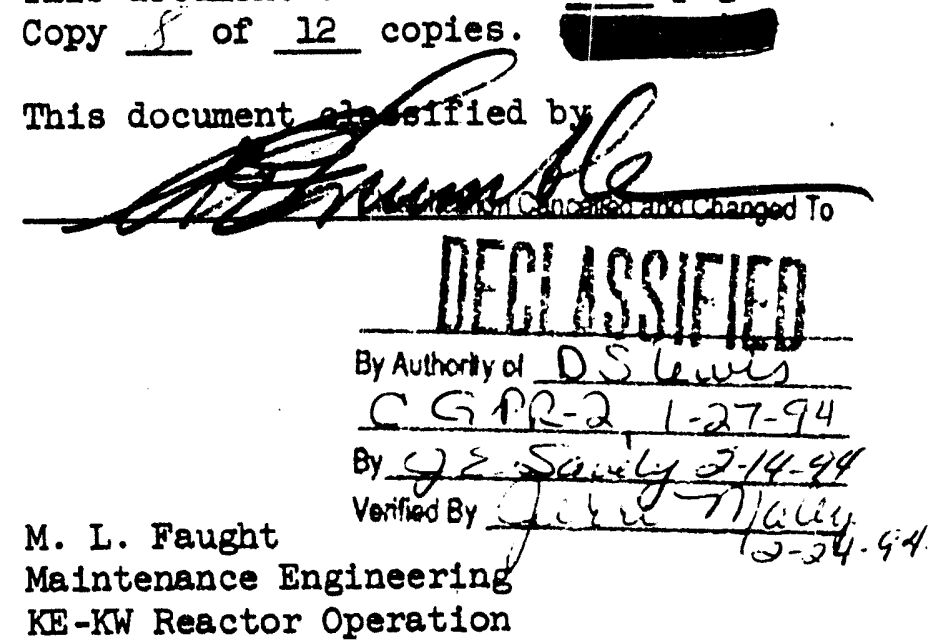

DISTRIBUTION

1. ML Faught

2. RS Bell

3. JH Brown

4. JM Fox, Jr.

5. RR Henderson

6. RW Reid

7. ER Rudock

8. HG Spencer

9. RE Trumble

10. GE Zima

11. Record Center

12. 300 File

\section{IRRADIATION PROCESSING DERARTMENT}

December 12,1960

\section{K REACTOR--HCR SLEEVES}
References
1) Letter, "Metallic HCR Sleeves," RS Bell to $J$ Brown, dated March 8, 1960.
2) Letter, "K Graphite--HCR Sleeves," ER Rudock to ML Faught, dated October 24, 1960.

The several conferences I have had with you and other.IPD people on the HCR sleeve problem at the $K$ Reactors have partially satisfied the information request tranamitted via reference 1 . In view of recent recommendations regarding this problem, outlined in reference 2, a brief sumary of our oplnions on the sleeves is in order, and long overdue. I apologize for the delay.

At the outset, 1t was felt that a partial sleeve would not preclude ball entry to an extent which could justify the partial sleeve work. The concept of using a tubular sleeve 1s, we feel, good from the standpoints of general sleeve strength and protection against ball entry. Furthermore a tubular sleeve has advantages with respect to procurement and ease of installation and removal.

The selection of a sleeve material, as with most reactor material problems, is not a black or white proposition. In our opinion, there are two factors which should govern selection of a sleeve material, namely: resistance to the chemical action of the in-pile atmosphere; and effect of sleeve material on pile reactivity. The chemical qualifications required of a sleeve material

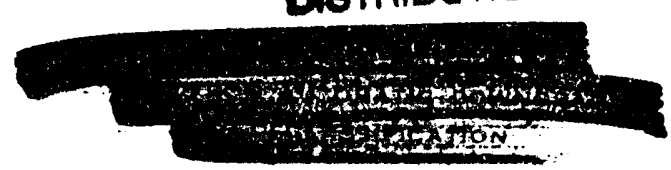


will depend on the expected temperature environment of the sleeve and the average composition of the in-plle atmosphere. Obviously, the more restrictive the temperature Iimits for acceptable service, the less desirable is the material. A sleeve which does not require cooling to maintain an acceptable level of chemical inertness would be at the high end of the merit scale providing it satisfies minimum acceptable reactivity requirements.

Over a period of time, the $K$ atmosphere will contain varlous chemically active species, including $\mathrm{CO}_{2}, \mathrm{CO}, \mathrm{H}_{2} \mathrm{O}, \mathrm{H}_{2}$, in various concentrations. If $\mathrm{N}_{2}$ is substituted for $\mathrm{CO}_{2}$ in the input gas, nitrogen oxides, nitrogen acids and possibly amonia, might be added to this list of active agents. An uncooled sleeve in the $K$ Reactors might attain maximum temperatures of the order of $800^{\circ} \mathrm{C}$ within 1 ts service ilfetime. To qualify as economical, an uncooled sleeve material should thus have good resistance to these agents up to temperatures the order of $800^{\circ} \mathrm{C}\left(1470^{\circ} \mathrm{F}\right)$. Depending on the extent to which it would be feasible to apply cooling to the sleeve, the maximum operating temperature could be backed down from the roughly $800^{\circ} \mathrm{C}$ level. In Table I, a brief appraisal is given of the abllity of some candidate materials to meet the chemical demands of sleeve service. It is to be emphasized that $\mathrm{Zr}-2$ is outside its area of serviceability when temperatures in excess of roughly $400^{\circ} \mathrm{C}$ are involved, under the expected atmosphere conditions. As indicated in Table I, from a chemical standpoint both Inconel and a 300 serles stainless steel, possibly 310, are considered practical possibilities for uncooled sleeve materials--with Inconel the preferred. material in our opinion.

R. D. Cahoon, of Reactor Physics, made rough estimates of the reactivity worth of various sleeve materials. These data are given in Table II. These estimates were made assuming all HCR channels sleeved. A tubular sleeve of 3.25" OD was used for these estimates. Reactivity worth may be adjusted roughly in proportion to wall thickness changes. Thus, an Inconel or stalnless steel sleeve of $1 / 20$ the thickness of a $\mathrm{Zr}-2$ sleeve would be expected to have roughly the reactivity worth of the $\mathrm{Zr}-2$ sleeve. More detailed reactivity calculations are in progress.

In sumary: It 1s believed that $\mathrm{Zr}-2$ would be a satisfactory sleeve material providing it is limited to maximum service temperatures the order of $400^{\circ} \mathrm{C}$. Both Inconel and a 300 series stainless steel are believed possibilities for uncooled sleeve materials, with Inconel our preference. Beryllium, in virtue of its outstanding nuclear properties and probably satisfactory chemlcal and mechanfcal properties, warrants consideration on a pllot basis if fabrication of a sultable sleeve form is practicable. Consideration of any sleeve material should include techniques for minimizing the friction between the sleeve and the control rod--particularly when a fretting-prone materlal, such as $\mathrm{Zr}-2$, is involved. A ball, or roller, bearing rod support, with a ceramic bearing contacting the sleeve, might be considered as a device for reducing sleeve wear and improving rod mantpulation.

The chemical and nuclear qualifications of $\mathrm{Zr}-2$, and the avallability of $\mathrm{zr}-2$ tubes of suitable size, justify the program outlined in reference 2 . We do not, 
however, consider that $\mathrm{Zr}-2$ avallability outwelghs the limited service temperature range of this material. The possibility that thin sleeves of Inconel, or stainless steel could render satisfactory service uncooled should, in our opinion, be given careful consideration along with $\mathrm{Zr}-2$.

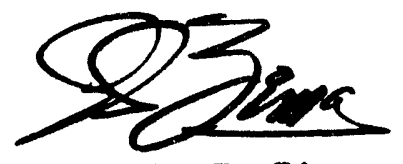

G. E. ZIma

Reactor Engineering

Process and Reactor Development

RESEARCH AND ENGINEERING

GEZ: vb 
M. I. Faught

$$
-4-
$$

HW -67382

Paght

\section{TABLE I}

Materlal

General Chemical Stability

General Strength Properties to Pile Atmosphere up to:

\begin{tabular}{|c|c|c|c|}
\hline & $400^{\circ} \mathrm{C}$ & $800^{\circ} \mathrm{C}$ & $400^{\circ} \mathrm{C}$ \\
\hline $\mathrm{zr}-2$ & good & poor & good \\
\hline Inconel & excellent & excellent & good \\
\hline 300 s.s. & excellent & good & good \\
\hline $\mathrm{Be}^{*}$ & excellent & good & good \\
\hline
\end{tabular}

November 9, 1960

TABLE II

\begin{tabular}{|c|c|c|c|}
\hline MateriaI & $\sum_{a}\left(\mathrm{~cm}^{-1}\right)$ & Reactivit & $\operatorname{th}(\mathrm{mk})^{*}$ \\
\hline & & $\frac{250 \mathrm{Mil} \text { Wall }}{(-)}$ & $\frac{100 \mathrm{M} 1 \mathrm{l} \text { Wall }}{(-)}$ \\
\hline $\mathrm{Zr}-2$ & 0.00687 & $\sim 0.5$ & \\
\hline Inconel & 0.323 & $\sim 8.0$ & $\sim 3.2$ \\
\hline 300 s.s. & 0.2 & $\sim 6.0$ & $\sim 2.4$ \\
\hline $\mathrm{Be}$ & 0.0011 & $\sim 0.1$ & \\
\hline Graph1te & 0.000221 & $\sim 0.0$ & \\
\hline $\mathrm{ZrO}_{2}$ & 0.00531 & $\sim 0.4$ & \\
\hline $\mathrm{Zl}_{2} \mathrm{O}_{3}$ & 0.0092 & $\sim 0.7$ & \\
\hline
\end{tabular}

*Assuming all HCR channels sleeved. Same sleeve size all materials (3.25"OD). 

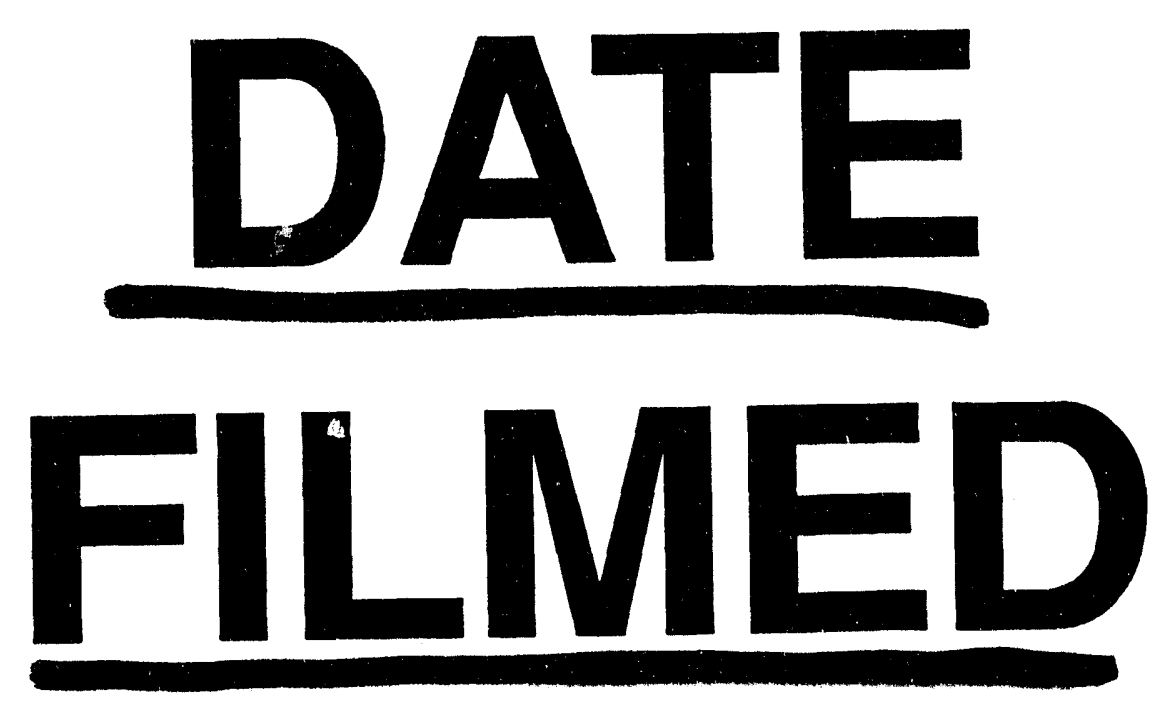

$$
7 / 19 / 94
$$
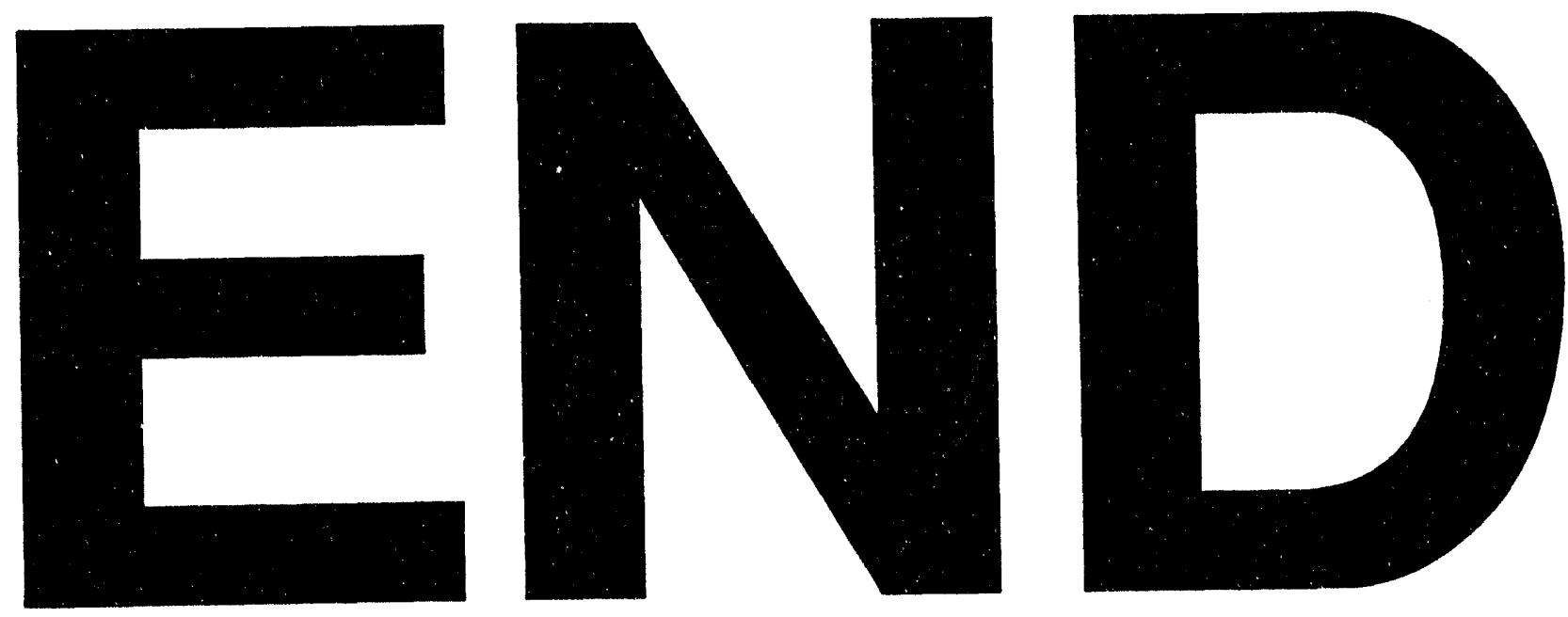


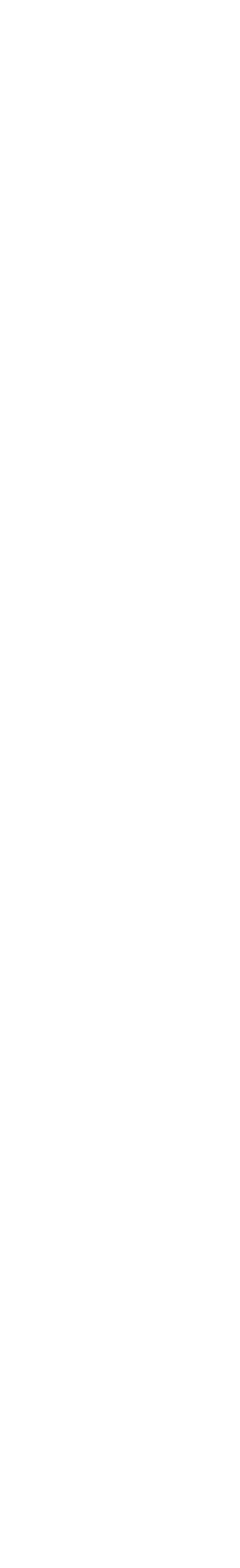

